\title{
ON THE MATHEMATICAL DESCRIPTION OF AN ACTIVATION ENERGY EVOLUTION
}

\author{
${ }^{1}$ Petr OPĚLA, ${ }^{1}$ Ivo SCHINDLER, ${ }^{1}$ Stanislav RUSZ, ${ }^{1}$ Horymír NAVRÁTIL \\ ${ }^{1}$ VSB - Technical University of Ostrava, Ostrava, Czech Republic, EU, petr.opela@vsb.cz
}

https://doi.org/10.37904/metal.2021.4073

\begin{abstract}
Activation energy at hot deformation represents a valuable physical quantity which finds its application e.g. in the case of a hot flow stress description. It has been showed that this quantity can be treated as a material constant, strain-dependent variable or even as strain, strain rate and temperature dependent variable. A mathematical description of the last and in the same time the most complicated dependency is the aim of the presented paper. Two mathematically different methodologies have been applied to cope with this issue - a multivariate polynomial relationship and an artificial neural network approach. The results have shown that the neural network approach represents an ideal one although the polynomial one is also applicable.
\end{abstract}

Keywords: Hot deformation activation energy, multivariate polynomials, artificial neural networks

\section{INTRODUCTION}

Since the $20^{\text {th }}$ century, so-called hot deformation activation energy, $Q\left(\mathrm{~J} \cdot \mathrm{mol}^{-1}\right)$, has been being applied for a description of hot flow curve (stress-strain) datasets which are usually experimentally acquired under various combinations of temperature and strain rate, i.e. curve fitting issue. This valuable physical quantity is predominantly treated either as a material constant (i.e. strain, strain rate and temperature independent) or as a strain-dependent variable. In the first case, the $Q$ is used for a mathematical description of significant flow curve points, i.e. a peak point, steady-state beginning or even dynamic recrystallization inception. Described coordinates of these significant points are then usually substituted as auxiliary variables into the flow stress models to fit an entire flow curve dataset - so the $Q$ is for the flow curve fitting applied indirectly (through the previous description of the significant flow curve points). In the second case, however, the $Q$ is employed for the flow curve fitting issue directly since it is considered to be strain dependent - this dependency is usually expressed via polynomial equations [1,2]. Nevertheless, some previous studies [3,4] have pointed out on the fact that the activation energy is actually dependent not only on the strain but also on the temperature and even strain rate. Naturally, there were attempts to embrace such dependency for an enhancement of current flow curve fitting solutions. Hand in hand with these efforts there were, of course, endeavors to mathematically describe the dependency of $Q$ on the strain, strain rate and temperature - practically solved only via multiple cooperating bivariate polynomials [3,4]. The aim of the submitted research is then introduce two new approaches which should bring an alternative possibility to cope with the Q-dependency complexity - a multivariate (specifically single trivariate) polynomial approach and an artificial neural network (ANN) one.

\section{EXTRACTION OF EXPERIMENTAL ACTIVATION ENERGY VALUES}

In order to demonstrate the above-mentioned approaches, an experimental hot-compression flow curve dataset of the manganum-vanadium steel has been selected. Experimental conditions are as follows: deformation temperatures of $1123,1273,1373,1473$ and $1553 \mathrm{~K}$, strain rates of $0.1,1,10$ and $100 \mathrm{~s}^{-1}$, and a true height strain reaching to 1.0. Laboratory details have been published previously in [5]. 
The selected hot-compression flow curve dataset has been subsequently utilized to gain experimental $Q$-values under all tested circumstances, i.e. $Q\left(\varepsilon, \varepsilon^{*}, T\right)\left(\mathrm{J} \cdot \mathrm{mol}^{-1}\right)$, via a regression analysis of the well-known Garofalo's relationship [6] - see equations (1) and (2) [7]:

$$
\begin{aligned}
& Q(\varepsilon, \dot{\varepsilon}, T)=\left.\left.R \cdot \frac{\partial \ln \dot{\varepsilon}}{\partial \ln \{\sinh [\alpha(\varepsilon, T) \cdot \sigma]\}}\right|_{\varepsilon, T} \cdot \frac{\partial \ln \{\sinh [\alpha(\varepsilon) \cdot \sigma]\}}{\partial(1 / T)}\right|_{\varepsilon, \dot{\varepsilon}} \\
& \alpha(\varepsilon, T)=\left.\frac{\partial \ln \dot{\varepsilon}}{\partial \sigma}\right|_{\varepsilon, T} /\left.\frac{\partial \ln \dot{\varepsilon}}{\partial \ln \sigma}\right|_{\varepsilon, T}
\end{aligned}
$$

In these equations, $\sigma(\mathrm{MPa}), \varepsilon(-), \varepsilon^{*}\left(\mathrm{~s}^{-1}\right)$ and $T(\mathrm{~K})$ represent a flow stress, true strain, strain rate and temperature, respectively. $R\left(8.314 \mathrm{~J} \cdot \mathrm{K}^{-1} \cdot \mathrm{mol}^{-1}\right)$ is the universal gas constant, $\alpha(\varepsilon, T)\left(\mathrm{MPa}^{-1}\right)$ and $\alpha(\varepsilon)\left(\mathrm{MPa}^{-1}\right)$ are a strain-temperature dependent and only-strain dependent stress multiplier, respectively [7].

\section{MULTIVARIATE POLYNOMIAL APPROACH}

In previously published studies (see e.g. [1]), a univariate polynomial expression [8] was successfully employed in order to fit a dependency between the activation energy and true strain. Since the activation energy is in the current research considered to be dependent also on the temperature and strain rate, a multivariate (specifically trivariate) polynomial expression has been proposed to cope with this approximation issue - its general form is expressed via the following equation:

$Q(\varepsilon, \dot{\varepsilon}, T)=\sum_{i=0}^{n} \sum_{j=0}^{n} \sum_{k=0}^{n} a_{i j k} \cdot T^{i} \cdot \ln ^{j} \dot{\varepsilon} \cdot \varepsilon^{k}$

In equation (3), $a_{i j k}(-)$ represent material constants, where $i=[0, n] \subset \mathbb{N}_{0}, j=[0, n] \subset \mathbb{N}_{0}$ and $k=[0, n] \subset \mathbb{N}_{0}$. While an ideal polynomial order, $n(-)$, was being found on the basis of a trial and error method, corresponding material constants were being calculated via the least squares method [9] in the Octave-4.2.1 programming environment [10]. Results have showed that an ideal order is equal to 3 , i.e. the equation (3) represents a tricubic polynomial - fitting constants are displayed in Table 1.

\begin{tabular}{|c|c|c|c|c|c|c|c|}
\hline$a_{i j k}$ & Value & $a_{i j k}$ & Value & $a_{i j k}$ & Value & $a_{i j k}$ & Value \\
\hline$a_{000}$ & $6.12 \cdot 10^{+03}$ & $a_{100}$ & $-1.24 \cdot 10^{+01}$ & $a_{200}$ & $8.73 \cdot 10^{-03}$ & $a_{300}$ & $-2.05 \cdot 10^{-06}$ \\
\hline$a_{001}$ & $2.30 \cdot 10^{+04}$ & $a_{101}$ & $-4.09 \cdot 10^{+01}$ & $a_{201}$ & $2.60 \cdot 10^{-02}$ & $a_{301}$ & $-6.07 \cdot 10^{-06}$ \\
\hline$a_{002}$ & $6.24 \cdot 10^{+04}$ & $a_{102}$ & $-1.43 \cdot 10^{+02}$ & $a_{202}$ & $1.03 \cdot 10^{-01}$ & $a_{302}$ & $-2.32 \cdot 10^{-05}$ \\
\hline$a_{003}$ & $-6.61 \cdot 10^{+04}$ & $a_{103}$ & $1.44 \cdot 10^{+02}$ & $a_{203}$ & $-1.01 \cdot 10^{-01}$ & $a_{303}$ & $2.26 \cdot 10^{-05}$ \\
\hline$a_{010}$ & $7.23 \cdot 10^{+02}$ & $a_{110}$ & $-1.46 \cdot 10^{+00}$ & $a_{210}$ & $1.01 \cdot 10^{-03}$ & $a_{310}$ & $-2.34 \cdot 10^{-07}$ \\
\hline$a_{011}$ & $-1.00 \cdot 10^{+04}$ & $a_{111}$ & $2.02 \cdot 10^{+01}$ & $a_{211}$ & $-1.39 \cdot 10^{-02}$ & $a_{311}$ & $3.23 \cdot 10^{-06}$ \\
\hline$a_{012}$ & $1.92 \cdot 10^{+04}$ & $a_{112}$ & $-3.87 \cdot 10^{+01}$ & $a_{212}$ & $2.67 \cdot 10^{-02}$ & $a_{312}$ & $-6.21 \cdot 10^{-06}$ \\
\hline$a_{013}$ & $-1.00 \cdot 10^{+04}$ & $a_{113}$ & $2.02 \cdot 10^{+01}$ & $a_{213}$ & $-1.40 \cdot 10^{-02}$ & $a_{313}$ & $3.27 \cdot 10^{-06}$ \\
\hline$a_{020}$ & $6.68 \cdot 10^{+01}$ & $a_{120}$ & $-1.47 \cdot 10^{-01}$ & $a_{220}$ & $1.07 \cdot 10^{-04}$ & $a_{320}$ & $-2.61 \cdot 10^{-08}$ \\
\hline$a_{021}$ & $-6.01 \cdot 10^{+02}$ & $a_{121}$ & $1.35 \cdot 10^{+00}$ & $a_{221}$ & $-9.83 \cdot 10^{-04}$ & $a_{321}$ & $2.37 \cdot 10^{-07}$ \\
\hline$a_{022}$ & $8.55 \cdot 10^{+02}$ & $a_{122}$ & $-2.03 \cdot 10^{+00}$ & $a_{222}$ & $1.52 \cdot 10^{-03}$ & $a_{322}$ & $-3.73 \cdot 10^{-07}$ \\
\hline$a_{023}$ & $-2.11 \cdot 10^{+02}$ & $a_{123}$ & $6.09 \cdot 10^{-01}$ & $a_{223}$ & $-4.95 \cdot 10^{-04}$ & $a_{323}$ & $1.27 \cdot 10^{-07}$ \\
\hline$a_{030}$ & $-2.31 \cdot 10^{+01}$ & $a_{130}$ & $5.10 \cdot 10^{-02}$ & $a_{230}$ & $-3.69 \cdot 10^{-05}$ & $a_{330}$ & $8.92 \cdot 10^{-09}$ \\
\hline$a_{031}$ & $5.28 \cdot 10^{+02}$ & $a_{131}$ & $-1.11 \cdot 10^{+00}$ & $a_{231}$ & $7.81 \cdot 10^{-04}$ & $a_{331}$ & $-1.85 \cdot 10^{-07}$ \\
\hline$a_{032}$ & $-1.04 \cdot 10^{+03}$ & $a_{132}$ & $2.19 \cdot 10^{+00}$ & $a_{232}$ & $-1.55 \cdot 10^{-03}$ & $a_{332}$ & $3.70 \cdot 10^{-07}$ \\
\hline$a_{033}$ & $5.42 \cdot 10^{+02}$ & $a_{133}$ & $-1.15 \cdot 10^{+00}$ & $a_{233}$ & $8.18 \cdot 10^{-04}$ & $a_{333}$ & $-1.96 \cdot 10^{-07}$ \\
\hline
\end{tabular}

Table 1 Material constants of the tricubic polynomial - equation (3) 


\section{ARTIFICIAL NEURAL NETWORK APPROACH}

Based on the previous successful implementations of an artificial neural network approach $[11,12]$ into the flow curve fitting process [7], a multi-layer feed-forward neural network [12] has been employed as an alternative to the above-mentioned multivariate polynomial approach. While an ideal network architecture was being found on the basis of a trial and error method, corresponding synaptic connections of artificial neurons were being calculated via the Levenberg-Marquardt algorithm $[13,14]$ cooperating with the Bayesian regularization $[15,16]$ under backpropagation of error signal [17]. It should be noted, fourteen $T-\varepsilon^{\prime}$ combinations have been used for the synaptic connection calculations while the rest of the dataset (i.e. six combinations) served for the subsequent testing of overfitting issue [12]. The described ANN solution has been realized under the Matlab 9.3 [18] programming environment with the embedded Neural Network Toolbox 11.0 [12]. An ideal network architecture is schematically displayed in Figure $\mathbf{1}$ and the corresponding legend is available in Table 2.

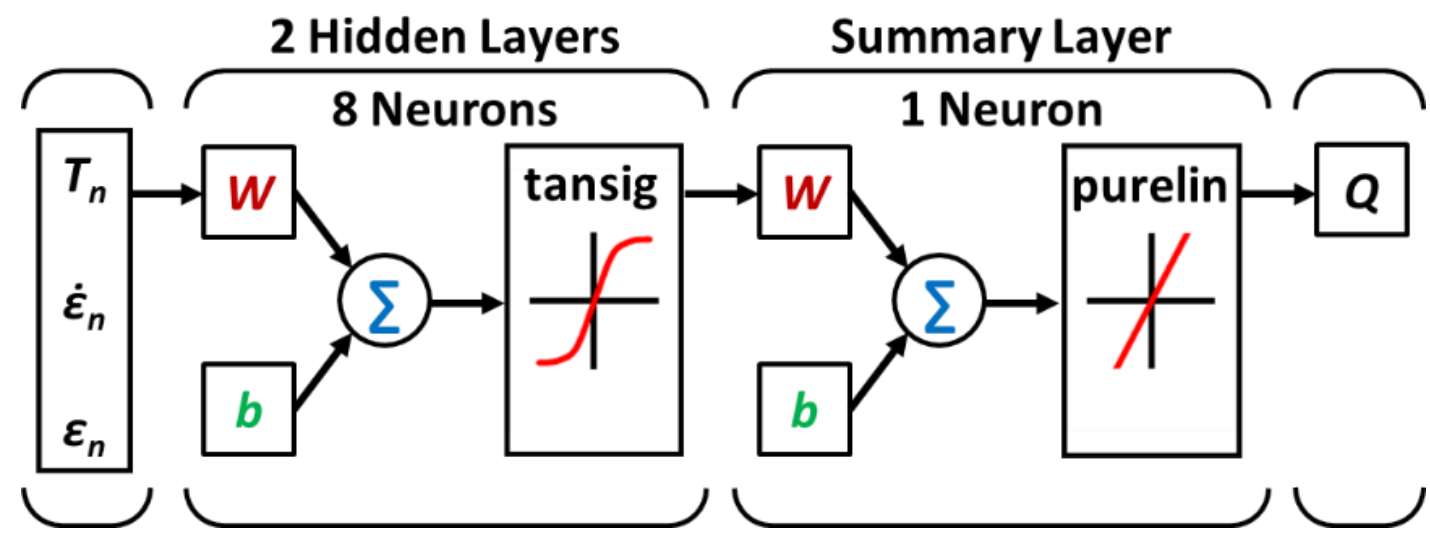

Figure 1 Block diagram of the utilized ANN architecture

Table 2 Legend of the block diagram in Figure 1

\begin{tabular}{|r|l|r|l|}
\hline Symbol & Meaning & \multicolumn{1}{|l|}{ Symbol } & Meaning \\
\hline$T_{n}(-)$ & $T$-vector normalized via a prestd [12] & $b(-)$ & Bias vector [12] \\
\hline$\dot{\varepsilon}_{n}(-)$ & $\mathcal{E}^{-}$-vector normalized via a prestd [12] & $\Sigma(-)$ & Weighted sum [12] \\
\hline$\varepsilon_{n}(-)$ & $\mathcal{E}$-vector normalized via a prestd [12] & tansig & Hyperbolic tangent sigmoid transfer function [12] \\
\hline$Q\left(\mathrm{~J} \cdot \mathrm{mol}^{-1}\right)$ & Q-vector & purelin & Linear transfer function [12] \\
\hline$w(-)$ & Synaptic weight matrix [12] & & \\
\hline
\end{tabular}

\section{RESULTS AND DISCUSSION}

Figures 2 and $\mathbf{3}$ offer a view on the $Q-\varepsilon$ course under various thermomechanical conditions. At the first sight it is evident that the activation energy is predominantly influenced by the strain and temperature level. The temperature influence is clear - the Q-level is decreasing with the increase of temperature. The strain dependency is, however, quite tricky. The $Q-\varepsilon$ curves (Figure 2) show under lower temperature levels behavior similar to the course of flow curves - see the intensive growth up to the global maximums (peaks) and subsequent gradual decrease. Another common feature is the earlier peak occurrence under lower strain rates and subsequent transition to steady-state. Similar flow-stress-like behavior has been observed e.g. in [7]. Nevertheless, the trends observed under lower temperatures are not in accordance with those observed under higher temperatures $-Q-\varepsilon$ curves seem to be mirror-inverted - they show a global minimum. Either way, the gained experimental $Q-\varepsilon$ curves have been successfully described via both above proposed approaches - see the solid and dashed lines corresponding with the ANN and polynomial approach, respectively (Figure 2). 
In addition, there is a prediction for two additional combinations of temperature and strain rate (gray curves) in order to verify a prediction capability. Despite of the good description via both approaches, the ANN one evidently exhibits the highest curve fit - the utilized tricubic polynomial relationship is not able to fit the experimental data with such precision. Note, the $3^{\text {rd }}$ polynomial order has been chosen as the best choice since lower and even higher orders exhibited much higher deviations.
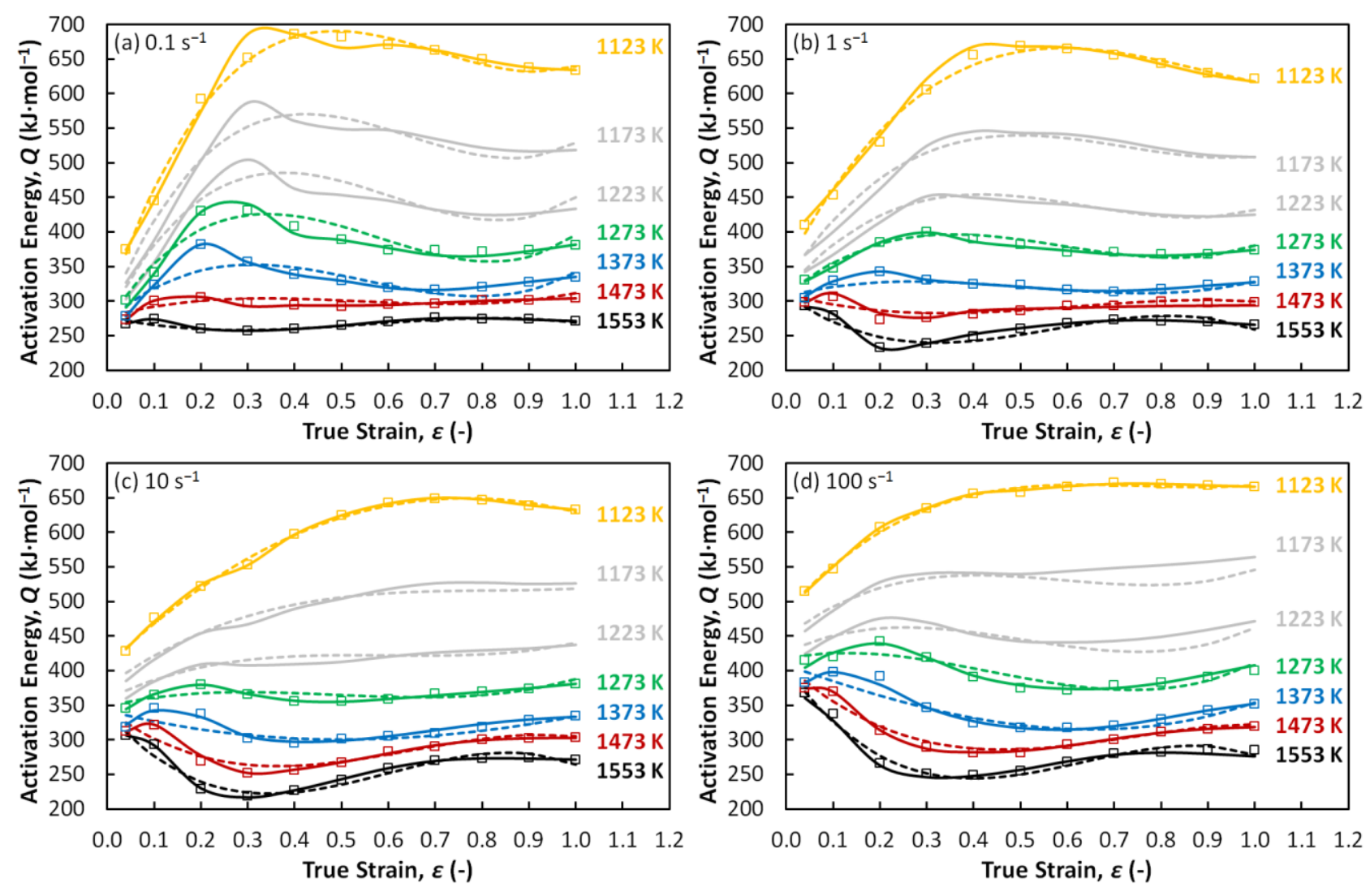

Figure 2 Comparison between the tricubic polynomial and ANN description; boxes - experimental data, solid lines - ANN, dashed lines - tricubic polynomial, color curves - approximation, gray curves - prediction
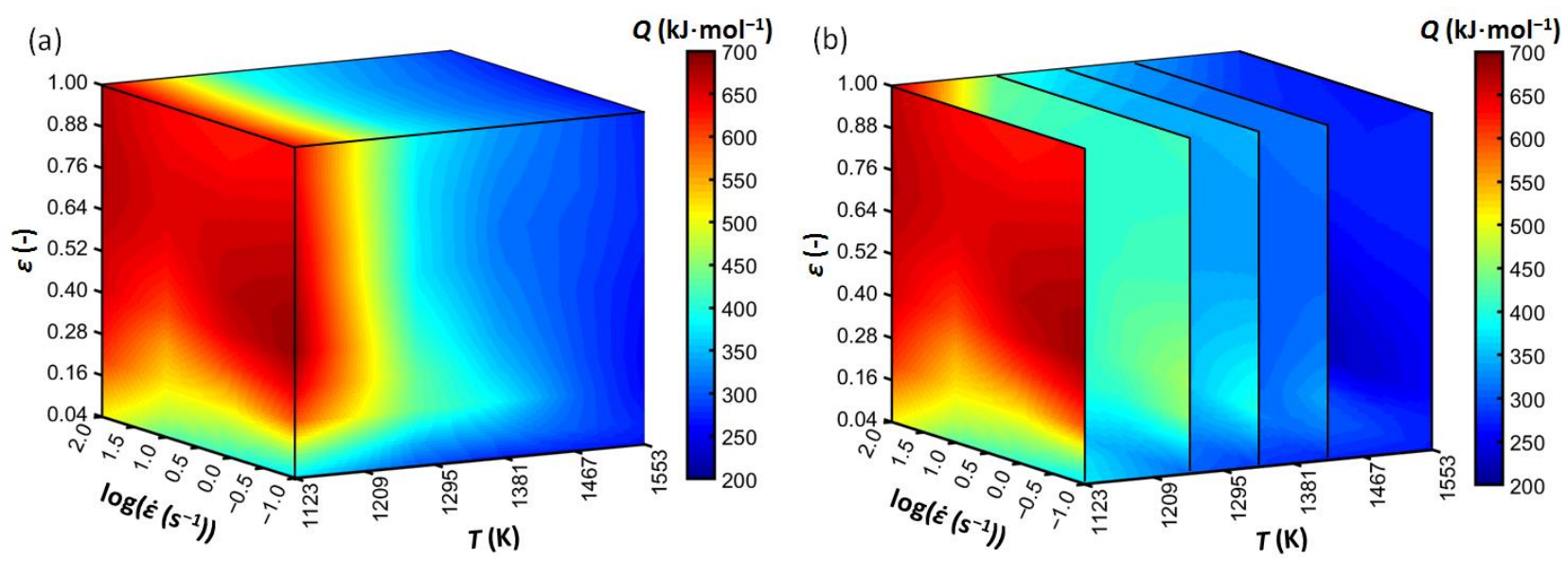

Figure 3 Volumetric expression of the activation energy evolution 
Figure 4 graphically expresses a statistical point of view on the applied approximation approaches. The compiled histograms offer a distribution of a relative percentage error, $\eta(\%)$ [19], corresponding mean value, $\mu(\%)[20]$ and standard deviation, $\sigma(\%)[21]$ :

$\eta_{i}=\frac{T_{i}-A_{i}}{T_{i}} \cdot 100$

$\mu=\frac{1}{n} \cdot \sum_{i=1}^{n} \eta_{i}$

$\sigma=\sqrt{\frac{1}{n} \cdot \sum_{i=1}^{n}\left(\eta_{i}-\mu\right)^{2}}$

The variables $T_{i}\left(\mathrm{~J} \cdot \mathrm{mol}^{-1}\right)$ and $A_{i}\left(\mathrm{~J} \cdot \mathrm{mol}^{-1}\right)$ symbolize the values of the target (experimental) and approximated $Q$-vectors, respectively, where $i=[1, n] \subset \mathbb{N}$ for $n$ corresponding with the number of vector elements. At the first sight it is obvious the $\eta$-values related to the ANN approach (Figure $\mathbf{4 b}$ ) are distributed in a narrower range (ranging from -4 to $6 \%$ ) than that corresponding with the tricubic polynomial relationship (Figure 4a) (ranging from -10 to $8 \%$ ) - a dispersion of the tricubic polynomial $\eta$-deviations is thus evidently higher. Another fact playing in favor of the ANN approach is that predominant amount of the $\eta$-deviations is in the case of the ANN approach higher than $-2 \%$ and at the same time lower than $2 \%$. Either way, it could be said that neither the ANN approach nor the tricubic polynomial shows inappropriately large values of $\eta$-deviation or values of $\mu$ and $\sigma$, and therefore both can find its place as a solution of the studied curve fitting issue.
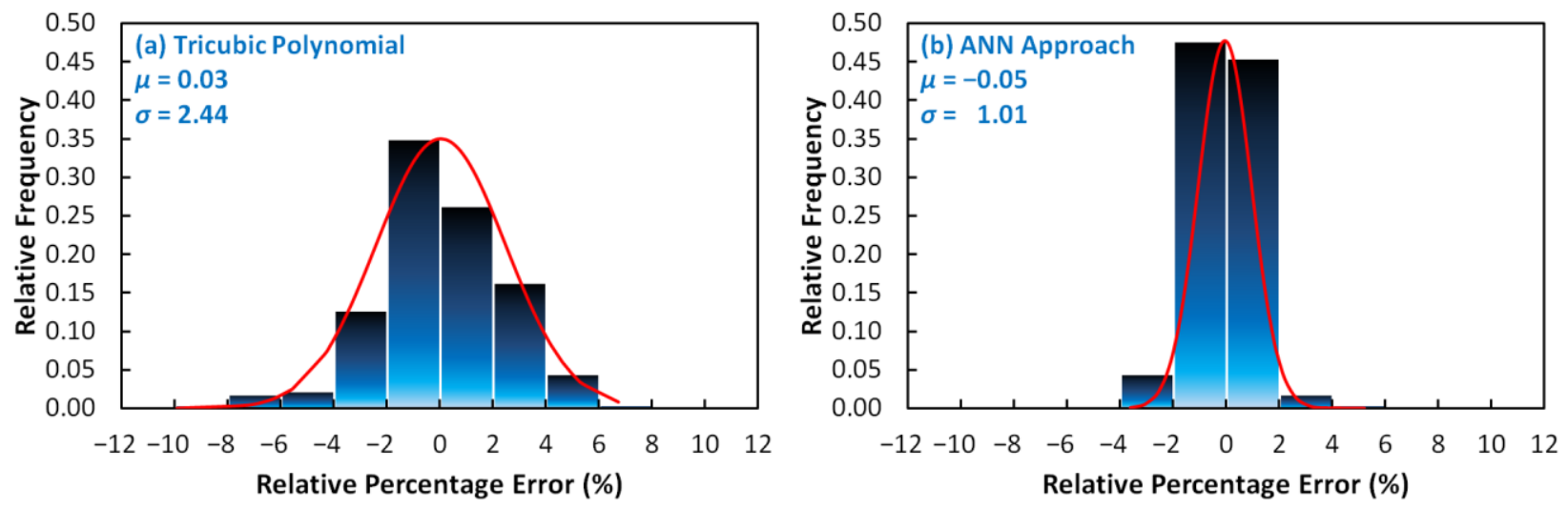

Figure 4 Distribution of the relative percentage error

\section{CONCLUSION}

In the frame of the submitted research, hot deformation activation energy was considered to be strain, strain rate and temperature dependent variable. Two entirely different mathematical approaches have been then introduced to cope with the corresponding approximation and prediction tasks. First of all, a regression analysis of the well-known Garofalo's relationship has been applied to gain the experimental activation energy values from a hot-compression flow stress dataset. Subsequently, the extracted experimental values of the activation energy have been described via a multivariate (specifically trivariate) polynomial relationship and an artificial neural network approach. With respect to the polynomial expression, a $3^{\text {rd }}$ order (which resulted in a tricubic polynomial) has been found to be the best one. A multi-layer feed-forward architecture under 2 hidden layers with 8 neurons, which were activated via a hyperbolic tangent sigmoid function, has been then selected as a best option in the case of the neural network methodology. Both applied approaches proved a good fit with the experimental dataset - although the neural network one has showed a slightly higher performance. Either way, both approaches have also provided a good prediction capability, and both can be considered for the practical utilization. 


\section{ACKNOWLEDGEMENTS}

\section{The article was created thanks to the project No. CZ.02.1.01/0.0/0.0/17_049/0008399 (ČR and EU financial funds) and the Student Grant Competitions SP2021/73 and SP2021/41 (MŠMT ČR).}

\section{REFERENCES}

[1] SHAFAAT, M.A., OMIDVAR, H., FALLAH, B. Prediction of hot compression flow curves of Ti-6Al-4V alloy in $\alpha+$ $\beta$ phase region. Materials \& Design. [online]. 2011, vol. 32, no. 10, pp. 4689-4695. https://doi.org/10.1016/j.matdes.2011.06.048

[2] SCHINDLER, I., KAWULOK, P., OČENÁŠEK, V., OPĚLA, P., KAWULOK, R., RUSZ, S. Flow Stress and Hot Deformation Activation Energy of 6082 Aluminium Alloy Influenced by Initial Structural State. Metals. [online]. 2019, vol. 9, no. 12, p. 1248. https://doi.org/10.3390/met9121248.

[3] MOHAMADIZADEH, A., ZAREI-HANZAKI, A., ABEDI, H.R. Modified Constitutive Analysis and Activation Energy Evolution of a Low-Density Steel Considering the Effects of Deformation Parameters. Mechanics of Materials. [online]. 2016, vol. 95, pp. 60-70. http://dx.doi.org/10.1016/j.mechmat.2016.01.001.

[4] LIU, L., WU, Y.-X., GONG, H., WANG, K. Modification of Constitutive Model and Evolution of Activation Energy on 2219 Aluminum Alloy during Warm Deformation Process. Transactions of Nonferrous Metals Society of China. [online]. 2019, vol. 29, no. 3, pp. 448-459. https://doi.org/10.1016/S1003-6326(19)64954-X.

[5] OPĚLA, P., SCHINDLER, I., KAWULOK, P., VANČURA, F., KAWULOK, R., RUSZ, S. New Model Predicting Flow Curves in Wide Range of Thermomechanical Conditions of 38MnVS6 Steel. In: METAL 2016: 25th Anniversary International Conference on Metallurgy and Materials. Ostrava: TANGER, 2016, pp. 458-463.

[6] GAROFALO, F. An Empirical Relation Defining the Stress Dependence of Minimum Creep Rate in Metals. Transactions of the Metallurgical Society of the American Institute of Mining, Metallurgical, and Petroleum Engineers. 1963, vol. 227, pp. 351-356.

[7] OPĚLA, P., SCHINDLER, I., KAWULOK, P., KAWULOK, R., RUSZ, S., NAVRÁTIL, H., JURČA, R. Correlation among the Power Dissipation Efficiency, Flow Stress Course, and Activation Energy Evolution in Cr-Mo LowAlloyed Steel. Materials. [online]. 2020, vol. 13, no. 16, p. 3480. https://doi.org/10.3390/ma13163480.

[8] DESCARTES, R. Discours de la méthode pour bien conduire sa raison, \& chercher la vérité dans les sciences. Plus la dioptrique. Les météores. Et la géométrie. [Discourse on the Method of Rightly Conducting One's Reason and of Seeking Truth in the Sciences. Plus the Diopter, Meteors and Geometry]. Leiden: De l'imprimerie de lan Maire, 1637.

[9] LEGENDRE, A.M. Nouvelles méthodes pour la détermination des orbites des comètes [New Methods for the Determination of the Orbits of Comets]. Mesnil-sur-l'Estrée: Firmin Didot, 1805.

[10] GNU Octave [online]. [viewed Nov 8, 2020]. Available from: https://www.gnu.org/software/octave/index.

[11] McCULLOCH, W.S., PITTS, W.H. A Logical Calculus of the Ideas Immanent in Nervous Activity. The bulletin of mathematical biophysics. [online]. 1943, vol. 5, no. 4, pp. 115-133. https://doi.org/10.1007/BF02478259.

[12] DEMUTH, H., BEALE, M. Neural Network Toolbox: For Use with MATLAB ${ }^{\circledR}$ [online]. [viewed Nov 9, 2020]. Available from: http://128.174.199.77/matlab pdf/nnet.pdf.

[13] LEVENBERG, K. A Method for the Solution of Certain Non-Linear Problems in Least Squares. Quarterly of Applied Mathematics. [online]. 1944, vol. 2, no. 2, pp. 164-168. https://doi.org/10.1090/qam/10666.

[14] MARQUARDT, D.W. An Algorithm for Least-Squares Estimation of Nonlinear Parameters. Journal of the Society for Industrial and Applied Mathematics. [online]. 1963, vol. 11, no. 2, pp. 431-441. https://doi.org/10.1137/0111030.

[15] BAYES, T. and PRICE, R. An Essay towards solving a Problem in the Doctrine of Chance. By the late Rev. Mr. Bayes, F. R. S communicated by Mr. Price, in a letter to John Canton, A. M. F. R. S. Philosophical Transactions of the Royal Society of London. 1763, vol. 53, pp. 370-418.

[16] MACKEY, D.J.C. Bayesian interpolation. Neural computation. [online]. 1992, vol. 4, no. 3, pp. 415-447. https://doi.org/10.1162/neco.1992.4.3.415. 
[17] RUMELHART, D.E., HINTON, G.E., WILLIAMS, R.J. Learning Internal Representations by Error Propagation. In: FELDMAN, J.A., HAYES, P.J., RUMELHART, D.E. (Eds). Parallel Distributed Processing: Explorations in the Microstructure of Cognition. Cambridge: The MIT Press, 1986, Volume 1: Foundations, chapter 8, pp. 318-362.

[18] MATLAB ${ }^{\circledR}$ Math. Graphics. Programming [online]. MathWorks ${ }^{\circledR}$ [viewed Nov 8, 2020]. Available from: https://www.mathworks.com/products/matlab.html.

[19] ABRAMOWITZ, M., STEGUN, I.A. Handbook of Mathematical Functions with Formulas, Graphs, and Mathematical Tables, $9^{\text {th }}$ ed. New York: Dover Publications, 1972.

[20] SIMPSON, T. A letter to the Right Honourable George Earl of Macclesfield, President of the Royal Society, On the Advantage of Taking the Mean of a Number of Observations in Practical Astronomy. Philosophical Transactions of the Royal Society of London. [online]. 1755, vol. 49, pp. 82-93. https://doi.org/10.1098/rstl.1755.0020.

[21] PEARSON, K. On the dissection of asymmetrical frequency curves. Philosophical Transactions of the Royal Society of London, Series A. 1894, vol. 185, pp. 719-810. 